\title{
ALZIRA. APUNTES PARA SU HISTORIA MEDIEVAL (SIGLOS XI-XIII)
}

\author{
Por \\ RAFAELA CASTRILLO MÁRQUEZ
}

Si otra gloria no tuviera Alcira musulmana, le bastaría con la de haber sido patria de hombres ilustres de la talla del poeta Ibn Jafāŷa o del filósofo Ibn Tumlūs, por no citar sino a los más afamados. Las más importantes colecciones biográficas de autores musulmanes enriquecen sus páginas con los nombres de aquellos alcireños que sobresalieron en actividades intelectuales. Y también los geógrafos se ocupan de hacer su descripción, resaltando siempre su condición de isla fluvial, situada entre los brazos del río Júcar, que es lo que ha dado precisamente origen a su denominación: al-Y̧azira, la Isla, la llamaron los árabes, o más concretamente, Ŷa azirat Šuqr, la Isla del Jucar.

Yāqūt -que junto a la grafía habitual de $\widehat{Y}$ azìrat Suqur da también las de $\breve{S} u k r$ y $\breve{S} a q r$ - dice que es «la más agradable de las comarcas de Dios y la que posee mayor abundancia de vergeles, árboles y agua» e inserta una poesía a ella dedicada por uno de sus naturales ilustres: Abū 'Abd Allāh Muhammad b. 'A' 'iša (1).

Al-Idrīisi la sitúa a 12 millas de Játiva y a 18 de Valencia y destaca la riqueza de sus árboles frutales, como hará siglos más tarde alHimyari. Ambos autores coinciden también en calificar a sus habitantes de «gentes de calidad». Al-Idrīsī nos facilita otro dato interesante: el paso por Alcira de los troncos talados en los pinares de Cuenca que, por vía fluvial, eran conducidos hasta Cullera (2).

Al-Himyari afirma que el único modo de llegar a Alcira en la estación invernal era por medio de barcas, $y$ en el verano por un vado.

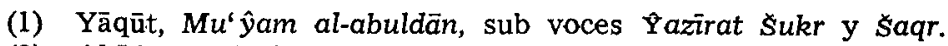

(2) Al-Idrīsī, Nuzhat al-Muštāq, ed. y tr. Dozy-De Goeje, Leydè, 1866, pp. 192 y 195, tr. pp. 233 y 237. 
Inserta luego una bella composición de Ibn Jafāŷa en la que el poeta, can nostalgia del pasado, va recordando los lugares donde transcurrió su juventud. Y otras dos de Ibn 'Ämira, escritas también en recuerdo de su ciudad, en las que la mención de las aguas azules del río Suq r forma contrapunto poético con el color rojo de los cabellos de sus nuevos señores, los cristianos (3).

La dificultad del ingreso a Alcira también la hacía constar ya en el siglo $\mathrm{VH}$. (= XI J. C.) al- $\mathrm{Ud}$ drī, refiriendo que «el río la rodea por todas partes sin que quede más que un paraje agradable por el que se pueda llegar a al-Yazira en el cual se ha construido un foso que está contiguo a un muro y a una puerta, a la que se entra por unas escaleras». Al-'Udrí es quien da la vocalización más correcta del topónimo: Y̧azirat Šsqar, que es como ha pasado a nuestro idioma (4).

En tiempos de al-Marrakušī - siglo VII H. (= XIII J. C.)debía existir un puente que facilitara el acceso, puesto que el autor así lo refiere (5).

Muchos han sido, pues, los musulmanes que se han ocupado de hacer en sus obras la descripción de Alcira, pero la pasión y el cariño, mezclados de nostálgico recuerdo, que pone Ibn Jafāŷa en sus versos siempre que a ella se refiere, supera cuanto de este lugar se haya escrito (6).

La historia de Alcira musulmana es particularmente interesante para nosotros a partir de los últimos años del siglo XI y, más concretamente, a partir del momento en que el Cid se posesiona de Valencia. Los pormenores de esta conquista son bien conocidos. Después de la caída de Toledo, en 1085, Alfonso VI promete al depuesto monarca al-Qādir —de la familia de los Banū Dì-l-Nūn y nieto del gran al-Ma'mūn - su ayuda para entronizarle en Valencia, ciudad de antiguo dependiente de Toledo y regida entonces por Ibn 'Abd al'Aziz. Con la ayuda de las tropas castellanas al mando de Alvar Háñez, y aprovechando la muerte de Ibn 'Abd al-'Azīz ocurrida ese

(3) Al-Ḥimyarī, al Rawḍ al-mi'țār, ed. y tr. Lévi-Provençal, pp. 102-104, tr. pp. 126 y s. La poesía de Ibn Jafāỳa que inserta al-Himyarì corresponde a la número 303 en la esmerada edición que del $D \bar{l} w \bar{w} n$ de este poeta ha hecho el Prof. Dr. Sayyid Gāzì (Alejandría, 1960).

(4) Al-'Udrī, Nuṣūṣ 'an al-Andalus min Kitāb tarsi' al-ajbār... al-masālik ilà ŷami al-mamālik, ed. al-Ahwānī, Madrid, 1965, p. 19. En el índice de lugares geográficos, en español, que lleva la edición, se encuentran indiferenciadas las referencias a Alcira y a Algeciras.

(5) 'Abd al-Wāḥid al-Marrakušĩ, al-Mu' ŷib, ed. Dozy, Leyden, 1847, p. 369, tr. Huici, Tetuán, 1955, p. 302.

(6) Ibn Jafầya, Dìwān, ed. Gāzì, vid., por ejemplo, poesías núms. 78, 156 y 277. 
mismo año, al-Qādir consigue instalarse en Valencia, inaugurando un reinado altamente impopular. A los pocos años, en 1092, estalla una revolución y al-Qādir es asesinado. El cabccilla de los revolucionarios es $\hat{\mathrm{Ya}} \mathrm{a}$ far $\mathrm{b}$. Yahhäf, ayudado precisamente por el gobernador almorávide de Alcira, Ảbū Nāșir. El Cid se erige en vengador del monarca asesinado y hace los preparativos para la conquista de Valencia, logrando su rendición tras la salida pacífica de los elementos almorávides que la defendían, al cabo de diecinueve meses y medio de asedio, en junio de 1094 (7).

El nombre de Alcira aparece varias veces en la historia cidiana. El año anterior a la toma de Valencia, cuando el Campeador, ante la amenaza de un desembarco de Yūsuf b. Tāsufūn en socorro de la ciudad, incita a su gobernador Ibn. Y̧ahhāf a formar una coalición antialmorávide, el alcaide de Alcira se niega a participar en ella. Para castigar su negativa, ordena Rodrigo hacer una incursión en sus tierras y apoderarse del trigo (8). Y posteriormente, a los tres años de la caída de Valencia, Alcira es escenario de la derrota de un contingente de tropas del Cid a manos de Ibn ' $\bar{A}$ 'iša, hijo de Yūsuf $b$. Tāšufin (9). Muerto el Cid y abandonada Valencia, los almorávides hicieron su entrada en esta ciudad el año $495 \mathrm{H}$. (= 1102 J. C.).

Algunos años después, el 519 H. (= 1125 J. C.), iniçia Alfonso I de Aragón su famosa expedición a la región levantina, en la que intentará, sin lograrlo, apoderarse de Alcira.

Cuando la parte oriental de la Península está bajo el dominio de Abū 'Abd Allāh Muhammad b. Sa'd b. Mardanīš el rey Lobo de nuestras crónicas-, paladín contra el poder almohade, es señor de Alcira, Ahmad b. Muhammad b. Ya'far b. Sufyān, el cual, descontento por el favor con que Ibn Mardanīš distinguía a los cristianos y temeroso de caer un día en desgracia y ser desposeído de su gobierno, se sublevó contra él y entró en negociaciones con los almohades. Ibn Mardanǐs, decidido a aplastar la rebelión, marcha contra Alcira y la pone cerco, en ell año $566 \mathrm{H}$. (= 1171 J. C.). A pesar de contar con el apoyo de su hermano Abūl-1-Haŷŷây Yùsuf, emir de Valencia, después de dos meses de asedio se ve obligado a retirarse ante los refuerzos que, al mando de Abū Ayyūb Muhammad b. Hilāl, acuden en auxilio de los sitiados.

Por entonces el poder de Ibn Mardanīš tocaba a su fin. Abundaban

(7) Cfr. R. Menéndez Pidal, La España del Cid, 6.a ed., Madrid, 1967, pp. 250 y ss. Vid. también sobre Valencia el interesante artículo del Profesor Dr. E. Terés, Textos poéticos árabes sobre Valencia, apud. Rev. "Al-Andalus», t. XXX (1965), fasc. 2, pp. 291-307.

(8) R. Menéndez Pidal, loc. cit., p. 370.

(9) Loc. cit., pp. 442 y ss. 
las defecciones de los que habían sido sus leales colaboradores e Ibn Hamušk, su propio suegro, le abandona por motivos familiares y se pasa a los almohades. Valencia, Almería, Lorca, Baza y también Alcira se entregan al almohade Abū Ya'qūo Yūsuf, e Ibn Mardanīš, refugiado en Murcia, muere allí el $567 \mathrm{H}$. (=1172 J. C.). Con ello «fue total la obediencia a los almohades en el Levante y su doctrina lo abarcó por completo», como afirma Ibn al-Jatīb (10).

Pasados los años y entrado en su ocaso el esplendor almohade, surge en al-Andalus la figura de Muhammad $b$. Yüsuf $b$. Hūd, miembro de la noble familia que un día dominara en Zaragoza. El año $625 \mathrm{H}$. (= $1228 \mathrm{~J}$. C.) se proclamó en Murcia amìr al-mu'mininn, reconociendo la autoridad califal de los 'abbāsies y titulándose alMutawakkil 'alà Allăh. Sus éxitos fueron tan rápidos y fulgurantes que en un corto espacio de tiempo se hizo dueño de casi toda la parte oriental española, con excepción de algunas comarcas (11). Alcira, con Játiva y Denia, fueron de las que se sometieron al nuevo señor. No así Valencia, regida primeramente por el almohade $A b \bar{u} S^{\top}{ }^{\top} \bar{d} d b$. Muhammad y luego por Abū Yamil Zayyān b. Mardanīš —descendiente del legendario Ibn Mardanǐs-, último rey musulmán de Valencia, quien acabó rindiéndola a Jaime I de Aragón mediante pacto, el año $636 \mathrm{H}$. $(=1238 \mathrm{~J}$. C.) $(12)$. Los términos de la capitulación son bien conocidos. El monarca aragonés se comprometía a proteger la salida de cuantos musulmanes quisieran abandonar la ciudad en el plazo de veinte días con dirección a Cullera o Denia, plazas cuya

(10) Cfr. Ibn al-Jațīb, A'māl al-a' lām, ed. Lévi-Provençal, Beyrouth, 1956, p. 262. Sobre Ibn Mardanīs, vid. también: Ibn Sa'id, Mugrib, ed. sawqī Dayf, El Cairo, 1953, t. II, pp. 250 y s. (Ibn Sa ${ }^{6} \overline{\mathrm{i}} \mathrm{d}$ escribe: Ibn Mardan̄̄̌s); al-Nașirī, K. al-Istiqșá, t. III, tr. Hamet, apud. Archives Marocaines, t. XXXII (1927), p. 103; al-Maqqarī: Nafh al-tīib, t. VI, pp. 112 y s.

(11) Cuando nombra heredero a su hijo Abū Bakr, recibe la adhesión de todas las regiones comprendidas entre Alcira y Algeciras, el $629 \mathrm{H}$. (= 1231/1232 J. C.). Cfr. Ibn 'I İārī, al-Bayān al-mugrib, tr. Huici, Los almohades, t. I, p. 334. Vid. también sobre este personaje alMaqqarī: Nafh al-tịb, t. VI, p. 118; Ibn Sa'īd, Mugrib, t. II, biogr. 518, pp. 251 y s.; Ibn al-Jațīb, $A^{\prime} m a \bar{l}$ al-a' lām, pp. 277 y ss.; El anónimo de Madrid y Copenhague, ed. y tr. Huici, Valencia, 1917, pp. 118 y s., tr. p. 139; I. de las Cagigas, Mudéjares, Madrid, 1949, t. II, pp. 347 y siguientes.

(12) Ibn 'Id̄ārì escribe que, en respuesta a una petición de socorro de Zayyān, el monarca hafșī de Túnez Abū Zakarivā', envió una flota en ayucia de Valencia con viveres, armas y ciinero, y al no poder desembarcar por causa del cerco, regresaron a Túnez después de dejar en Denia las armas y los viveres. Cfr. al-Bayān al-mugrib, tr. Huici, Los almohades, t. II, pp. 124 y s. Vid. también al-Maqqarī, Nafh al-țîb, ed. El Cairo, t. VI, p. 204; al-Ḥimyarī, al-Rawd al-mi țār, ed. LéviProvençal, p. 48, tr. p. 61. 
posesión se había reservado Zayyān, y respecto a las cuales se había acordado una tregua de siete años (13). Se afirma que fueron más de cincuenta mil los que se exiliaron voluntariamente. A los que optaron por quedarse, se les garantizaba su seguridad y la práctica de su fe y costumbres (14).

Ya hemos anotado que Alcira quedaba fuera de la jurisdicción de Zayyān y, por lo tanto, de momento, no corrió la suerte de Valencia y de las otras plazas sometidas al mismo, que hubieron de ser entregadas, y cuyo límite geográfico lo constituía la margen izquierda del Júcar, según afirma Gómez Miedes: «Zaen no se obligo a entregar las de la otra parte del mismo Rio, porque como era Rey nueuo y mal quisto no se hauia estendido sobrellas su mando, ni estauan por el» (15).

Pero como era fácil de prever, don Jaime no iba a detener su anhelo de conquista en el río Júcar. Y pronto Alcira había de correr la misma suerte que las otras plazas caídas ya en poder de los cristianos. Al-Himyarī inserta sendas epístolas de Ibn 'Āmira y de Ibn al-Abbār escritas con motivo de la pérdida de Valencia. En la primera de ellas dice su autor que, después de la caída de Valencia, «la tropa de infieles lanzó sus soldados rubios, de ojos azules, que cercaron la isla de Šuqr». Las palabras de Ibn al-Äbbār, llenas de un lirismo triste, nos hablan también de la expansión de la conquista aragonesa hasta Alcira (16). Las fuentes cristianas nos proporcionan abundantes datos sobre este punto. En primer lugar contamos con el extenso relato que el propio rey hace en su Crónica. En ella refiere cómo el gobernador de Älcira huyó de la fortaleza al enterarse de los propósitos de conquista que él abrigaba. Al quedar desamparados, los habitantes envían mensajeros al monarca para expresarle sus deseos de entrega pacífica. Después de varias negociaciones promete don Jaime respetar sus vidas, fe y costumbres, mientras los de Alcira, por su parte, se comprometen a entregar una de las torres $-y$ poco después las otras dos-, situadas junto a la puerta de Valencia, y al pago de los mismos impuestos que venían satisfaciendo a su ante-

(13) Ibn 'Iḍārī reduce a cinco el número de años de la tregua. Cfr. al-Bayān al-mugrib, tr. Huici, Los almohades, t. II, p. 125.

(14) Vid., por extenso, el relato de la entrega de Valencia apud Jaime I, rey de Aragón, $H^{a}{ }^{a}$ del rey de Aragón D. Jaime I el Conquistador..., tr. M. Flotats y A. Bofarull, Barcelona, 1848, pp. 261-265; B. Gomez Miedes, La historia del muy alto e invencible rey Don Jaime de Aragón, Valencia, 1584, pp. 236 y ss.; F. Diago, Anales del Reyno de Valencia, Valencia, 1613 , t. I, ff. 316 v y 317 r.

(15) Cfr. B. Gómez Miedes, La historia del... rey Don Jaime de Aragón, p. 241.

(16) Cfr. al-Ḥimyarī, al-Raẉ̣ al-mi'tāar, ed. Lévi-Provençal, pp. 49 y 52 y ss.; tr. pp. 62 y 66 y ss. 
rior gobernador (17). El monarca hacía también una concesión: que ningún cautivo refugiado en Alcira pudiera ser reclamado ni aun por el propio rey. De parecido derecho gozaron también otras morerías valencianas (18).

Escolano y Gómez Mićdes se expresan en términos parecidos. Este último explica la fuga del gobernador de Alcira como motivada por el" temor de que don Jaime se hubiera enterado de los tratos secretos que mantenía con los castellanos, a quienes pensaba rendir la plaza, y quisiera descargar en él su cólera (19).

Por lo que respecta a la fecha de la conquista de Alcira, hay fluctuaciones en las fuentes. Al-Maqqarī, en una breve referencia, sitúa la rendición a finales del año $639 \mathrm{H} .(=1242 \mathrm{~J}$. C. $)$, y añade que tuvo lugar «en paz» (sulhan), es decir, mediante capitulación, empleando el mismo término que unas páginas antes había utilizado al referirse a la conquista de Valencia. Zurita y Escolano, por su parte, sitúan el suceso en el año 1245 (20).

No había transcurrido mucho tiempo desde que Alcira capitulara cuando debieron presentarse los primeros conflictos derivados de la convivencia entre musulmanes y cristianos, por causa de las heredades que unos y otros poseían en la villa y su término. Ordena entonces Jaime I, para solventar las diferencias, que les sean devueltas a los sarracenos las que les hubieren sido arrebatadas violentamente y establece normas para prevenir futuros altercados (21). A esta misma finalidad de evitar los conflictos que pudieran surgir entre las comunidades mudéjar y cristiana de las diferentes localidades valencianas,

(17) Sobre la topografía alcireña, vid. J. Ribera, Topografía de Alcira árabe, apud. Rev. "El Archivo», t. II (1887-88), pp. 54 y ss.

(18) Vid. M. Gual Camarena, Mudéjares valencianos, apud. Rev. «Saitabi», año IX (1949), t. VII, núm. 33-34, p. 171.

(19) Vid. Jaime I, rey de Aragón, Historia, tr. Flotats y Bofarull, pp. 293-295;

B. Gómez Miedes, La historia del rey Don Jaime de Aragón, p. 303; G. Escolano, Décadas de la historia de... Valencia, Valencia, 1879, t. II, p. 391.

(20) A.l-Maqqarì, Nafh al-țìb, t. VI, p. 215; G. Escolano, Décadas, t. II, p. 391. Don Roque Chabás, a quien se deben numerosos estudios sobre la historia de la región levantina, fija la entrada de Jaime I en Alcira la vispera de San Silvestre —es decir, el 30 de diciembre- del año 1242. Cf. Sección de Documentos, apud «El Archivo», t. II (1887-88), p. 270; y Alcira y su Archivo Municipal, apud «El Archivo», t. VI (1892), p. 217.

(21) El documento fue otorgado en Játiva el 18 de julio de 1245 y se conserva en el Archivo Municipal de Alcira. Ha sido publicado por A. Huici en su Colección diplomática de Jaime $I$ el Conquistador, Valencia, 1916, t. I, doc. CCCIII, pp. 419 y ss., y por José Maria Parra Ballester en Pergaminos de la Cancillería real del Archivo municipal de Alcira, Alcira, 1967, doc. n. 1, pp. 1 a 8. 
tenderán las sucesivas disposiones de los monarcas, prohibitivas de morar en común (22). La población musulmana en la región valenciana vivía normalmente en barrios separados $\mathrm{y}$, vara mayor aislamiento $\mathrm{y}$ salvaguardia, murados. En Alcira los propios habitantes de la morería son los que solicitan sea levantado en ésta un muro para su protección (23). Sin embargo, el hecho de que distintos monarcas insistan en la separación de morada de ambos núcleos de población, indica que las nedidas prohibitivas no siempre fueron observadas y que, en la práctica, la convivencia debió ser frecuente (24).

La población mudéjar estaba sujeta al pago de tributos especiales, además de otros cuyo gravamen compartía con los cristianos. Jaime I, en 1257, fija en 100 besantes la contribución de los musulmanes de Alcira, dentro de la relación general de impuestos que correspondía pagar a las distintas comunidades mudéiares del reino de Valencia. Esta aportación es de las menores ya que, según consta en la misma relación, los de Uxó habían de satisfacer 600 besantes y los de $\mathrm{Al}$ fandec de Mariynen, 800 (25). En ocasiones, los monarcas eximían: individual o colectivamente a los musulmanes del pago de determinados impuestos. Así, el citado rey, en 1270 libera a los de Alcira que labren tierras en Campanar del pago del besante anual y, en 1274, exime durante cuatro años de las peitas o tributos de carácter personal -que habían de pagar al igual que los cristianos-, a los sarracenos que acudan a poblar Alcira (26).

(22) Sobre el término «mudéjar», vid. I. de las Cagigas, Los mudéjares, t. I, pp. 57 y ss.

(23) Vid. L. Piles, La situación social de los moros de realengo en la Valencia del siglo $X V$, apud «Estudios de historia social de España:, t. I (1949), p. 233 y nota 7.

(24) En 1276 ordena Pedro el Grande a los Justicias del reino de Valencia que no permitan cohabitar cristianos con sarracenos (Doc. del Arch. de la Corona de Aragón, publicado por $F$. Roca Traver en Un siglo de vida mudéjar en la Valencia medieval 1238-1338, Zaragoza, 1952, p. 193. Martín I, en 1409, prohibe a los cristianos de Valencia habitar dentro. de la morería (Cf. F. Roca Traver, loc. cit., p. 125). Vid. también L. Piles, La situación social..., p. 233; M. Gual Camarena, Mudéjares valencianos, p. 170.

(25) Documento del Arch. de la Corona de Aragón, publicado por R. Chabás en «El Archivo», t. I (1886-87), p. 255. El besante - según definición de Gual Camarena- era el derecho que el monarca percibia anualmente por cada sarraceno. Cf. Mudéjares valencianos, pp. 186 y ss Vid. también sobre la cuestión tributaria, L. García de Valdeavellano, Curso de Historia de las instituciones españolas, Madrid, 1968, pp. 308 y 602 y ss.

(26) Documentos del Archivo de la Corona de Aragón. Vid. J. E. Martínez Ferrando, Catálogo de la documentación del antiguo reino de Valencia. Madrid, 1934, t. I, docs. 1019 y 1706. 
Jaime I conoció los grandes levantamientos de los mudéjares valencianos, acaudillados por Alazarch, como le llaman las fuentes, y murió antes de poder sofocar el último de ellos, legando a su hijo la tarea de la pacificación del reino. Para terminar con su estado de agitación, determinó el monarca expulsar a toda la población musulmana y dio una orden en tal sentido. Fueron muchos los que hubieron de expatriarse, sin que influyeran en el ánimo del rey para hacerle desistir de su propósito, los ofrecimientos de nuevos impuestos que le hicieron los afectados ni la oposición de algunos señores que veían perjudicados sus intereses con dicha medida. El número de los expulsados fue muy grande. La Crónica del monarca habla de «cinco leguas desde la vanguardia de la comitiva hasta la retaguardia», como extensión de la larga fila que formaban, en su camino hacia Villena, portando cada uno cuantos bienes y enseres podían acarrear (27).

Sin embargo, fueron muchos también los mudéjares que siguieron permaneciendo en el reino. Aunque Diago cifra en cien mil el número de los que lo abandonaron, dice que el rey «dissimulaua con los que en numero extraordinario se quedauan en el [reino] por dar gusto a los ricos hombres y caualleros que siempre procuraron valerles por sus intereses» (28). Los que continuaron residiendo en el reino, nuevamente provocaron otra sublevación poco tiempo después, que no pudo ver sofocada por haberle sorprendido antes la muerte. Hallándose precisamente en Alcira y sintiéndose enfermo, mandó llamar a su hijo don Pedro para darle las últimas instrucciones, recomendándole muy encarecidamente que llevara a cabo la total expulsión de los mudéjares.

De las distintas ocasiones que Jaime I estuvo en Alcira, recoge Diago su estancia del año 1270 , en cuyo momento ordenó la construcción de la acequia nueva, y su posterior viaje a la villa, de 1272, para celebrar Cortes en ella (29).

A la muerte de este monarca, ocurrida el 1276, quedaba por resolver, como hemos dicho, la cuestión de los mudéjares valencianos, en plena sublevación. Por lo que respecta a Alcira, esta sublevación tuvo una consecuencia de particular interés. Dio ocasión a que, aprovechando la oportunidad del momento, por hallarse don Pedro ocupado en sofocar la revuelta y los ánimos de las gentes excitados contra el elemento musulmán, la población cristiana de la villa llevara a cabo el saqueo de la morería. La fecha del suceso no es bien conocida.

(27) Sobre los pormenores de la expulsion y su fecha, vid. Jaime I, rey de Aragon, Historia, tr. Flotats y Bofarull, pp. 315 y ss.; G. Escolano, Décadas, pp. 607. y ss.; B. Gómez Miedes, La historia del... rey Don Jaime, pp. 335 y ss.; F. Diago, Anales, t. I, ff. $344 \vee$ y ss.

(28) F. Diago, loc. cit., f. 373 v.

(29) F. Diago, loc. cit., ff. 378 v y 381 v. 
Chabás la limita entre la muerte de Jaime I, en julio de 1276, y el indulto concedido a la villa por su sucesor, otorgado en junio de 1279 , inclinándose a pensar que fuera incluso anterior a la toma de Montesa, último reducto de los mudéjares rebeldes, en septiembre de 1277 (30). Esta opinión puede concretarse aún más a la luz de los documentos relativos a este acontecimiento, que se conservan en el Archivo de la Corona de Aragón y que insertamos como Apéndice. El primero lleva la fecha del 26 de junio de 1277 y va dirigido al Justicia de Alcira, a fin de que haga comparecer a diversos individuos acusados de haber figurado entre los asaltantes. Por lo tanto, sabemos ya con certeza que el saqueo de la morería tuvo lugar antes de esta fecha.

Según consta también en los referidos documentos, conocemos el castigo pecuniario que el monarca impuso a la villa por el saqueo de la morería. La cantidad a que ascendía el mismo era, en un principio, de 15.000 sueldos reales, rebajados posteriormente a 10.000 (31). Martín de Seta fue la persona designada como colector para hacer efectiva la suma, con la orden expresa de embargar los bienes de los que no pudieran pagar su parte. Solamente había de exceptuar a los caballeros, libres de este gravamen (32). En junio de 1279 concede don Pedro el real perdón a Alcira y su término, quedando zanjado con ello el incidente. No obstante, en este último documento se hace constar que no han de ser incluídos en la remisión de penas ni el Baile, ni el Justicia y los demás oficiales reales (33).

Casi todos los autores coinciden en reconocer como causa principal de los saqueos que se produjeron en las morerías de las distintas localidades, el afán de pillaje y no el motivo religioso. El asalto a la morería de Alcira afectó no sólo a los mudéjares de la villa sino a los que habitaban en las alquerías de su término, y no se limitó a los bienes y pertenencias sino que se vieron afectados incluso en sus personas, como se desprende de la lectura del indulto de 1279. En el saqueo debieron tomar parte también vecinos de localidades próximas, o al menos la sospecha debió existir, dando motivo a que el monarca expidiera el 1 de abril de 1278, un documento dirigido a Martín de Seta en el que se le ordena compruebe la no participación de los

(30) R. Chabás, Documentos, apud «El Archivo», t. II (1887-88), pp. 272 y siguientes.

(3I) Vid. infra, Apéndice, doc. nüm. 2.

(32) Loc. cit., docs. núms, 4 y 6.

(33) Chabás interpreta esta decisión real como motivada por la participación delictiva de las autoridades en el saqueo, siquiera fuera por su actitud pasiva ante el mismo. Como publica, transcrito y traducido, el documento del indulto, no lo insertamos en nuestro Apéndice. Cf. Documentos, apud «El Archivo» t. II (1887-88), p. 272. 
vecinos de Carcagente, Ternils y Algemesí en el asunto de Alcira y, una vez comprobada, se les exima de culpa (34).

El caso de Alcira no debió ser único en el siglo XIII. El documento en el que se ordena a Martín de Seta el embargo de bienes de aquellos que no puedan pagar la multa, prescribe también, al mismo tiempo, que se proceda en igual forma con los vecinos de Murviedro que hubieran intervenido en el saqueo de la morería de Liria (35).

La población mudéjar valenciana siguió, no obstante, prestando su apoyo al monarca. El mismo Pedro el Grande acude a ellos en solicitud de ballesteros y lanceros con que incrementar sus huestes en la lucha que mantenía con los franceses, prometiendo recompensarles con el pago de buena soldada (36).

Acabado el reinado de dicho monarca - muerto el año 1285--, llegamos al tope cronológico que nos hemos marcado en nuestro trabajo. Ha sido nuestra intención a lo largo de estas páginas, esbozar los principales momentos históricos vividos por Alcira y su población musulmana desde finales del siglo XI hasta casi concluído el XIII, dejando a un lado, intencionadamente y por razones de brevedad, aspectos importantes de índole social y política. Remitimos al lector interesado, a los estudios de los diferentes autores que homos ido citando, relativos al reino de Valencia en general y a su población mudéjar.

(34) Vid. infra, Apéndice, doc. núm. 5.

(35) Los casos de Alcira y Líria pueden citarse, pues, como excepciones a la afirmación de Roca Traver de que «los asaltos a las morerías valencianas perpetrados en los siglos XIV y XV en modo alguno puditron darse en el XIII». (Un siglo de vida mudéjar, p. 119.) Vid. J. E. Martinez Ferrando, Catálogo de la documentación relativa al antiguo reino de Valencia, $t$. II, doc. 353 .

(36) Vid. Colección de documentos inéditos del Archivo de la Corona de Aragón, publ. por P. Bofarull, t. VI, p. 195. 


\section{APENDICE}

\section{Documentos del Archivo de la Corona de Aragón relativos al saqueo de la morería de Alcira. Reinado de Pedro el Grande (1)}

Valencia, 26, junio, 1277.

(Reg. 39, fol. 210 v)

Orden a Ermengaudo, justicia de Alcira, de que cite a comparecer a diversos individuos, cicusados de haber tomado parte en el saqueo de la morería de la villa

P[etrus], Dei gratia Rex Aragonum, fideli suo Ermengaudo iusticie Algesire, saiutem et gratiam. Mandamus vobis quod visis pre- / sentibus assignetis ex parte nostra diem martis proximan venturam peremptoriam ad proponendum et dicendum quicquid (sic) proponere / vel dicere voluerint coran Raymundo de Minorisa vbicumque nos fuerimus contra inquisitionem factam super barrigio morerie [ ] / istis qui secuntur. R[aymundo] Segarre, Berengario Vrgelis, Pletro] de Elgana, Berengario de na Mandonia Barraquer, Dommico Gasco, Berengario / Pelicer, Iusto (?) Banat, Dommico Batitzato, Martino F. Batitzato, Dommico Xotelado, Dommico de Glarini, Bernardo de Aldaurax, / Therese uxori quondam Micchel, P[etro] Dolit, Bernardo de na Barçalona, R[aymundo] Texidor, Bernardo qui moratur cum / Iacobo Escuder, Aparcero Galidon, Martino de Spessa, F[errando] Traginer marito de na Amada, / Micheli qui moratur cum Ferrando Sanxis, Iohanni Amoret marito de na Catarina, Tacobo qui moratur / cum Iohanne de Tuyol, P[etro] Fuster, Dommico Gil, Gluillelmo] de Cannades, Dommico Cavalerii, Berengario de Nepes (?), Bondia Banaten Cabrari (?) / Bernardo de Calidis en Calderes, F[errando] Myr, similiter filiis de na Cabrari, B[ernardo] de Calidis qui moratur in ravali, filio d'en Camaco (?) / et matri eius Garbana, P[etro] Ianuarii, filio d'en Gil Tafur, B[ernardo] Marsol, Andree Dunola, Francisco filio P[etri] Sancii, G[uillelmo] de / Cilla, Nicholae uxori quondam Uraqueti (?), Romeo Previgno d'en Frayana, Berengario de Calidis, G[uillelmo] Venrel, Romeo Porta, P[etrol Goneli (?), R[aymundo] de Ture, Micheli Ferrand, Martino de Carcastello, P[etro] Ermengaudi, Iohanni de Buyol, P[etro] Paschali Galindo, Berengario

(1) Los documentos que a continuación transcribimos, corresponden a los núms. 242, 328, 329, 340, 352 y 372 del Catálogo de Martînez Ferrando (t. II). De esta obra recogemos los epígrafes que van en cursiva. 
de na / Mandonia, Raymundo de Poale, uxori Martini de Nula, P[etro] Rossel, Gluillelmo] de Anglada, Paschali de Alcudia de Carlet, Ferrando / Sancii, Marco Galindo. Datum Valencie, VI kalendas iulii anno Domini M.CC.LXX septimo.

\section{2}

Valencia, 12, febrero, 1278.

(Reg. 40, fol. 63)

Orden a Rodrigo Jiménez de Luna, procurador del Reino de Valencia, de que cobre a los vecinos de Alcira solamente 10.000 sueldos reales, en vez de 15.000, a que subía en un principio la cantidad que se les impuso como castigo

P[etrus], Dei gratia Rex Aragonum, [nobili] et dilecto Roderici Exemeni de Luna, procuratori Regni Valencie uel collectori denariorum condemnacionis Algeçire, / salutem [et gratiam] [ ] speditim (?) ad instanciam et preses carisima consorti nostre rexine Mayoris, absolvimus et [ ] / hominum (?) de Algeçire quinque M. solidorum de illis quindecem milibus solidorum in quibus ipsa vniuersitas vobis extitit / per sententiam condemnata. Quare mandamus vobis quatenus ab ipsis hominibus de Algeçira non petatis seu exigatis de inde per ipsam / condamnacionem nisi tamen decem milia solidorum. Datum Valencie, pridie idus februarii anno Domini M.CC.LXX.VII.

Valencia, 13, febrero, 1278.

(Reg. 40, fol. 63)

Orden al mismo Ródríguez Jiménez de Luna, de que absuelva a Gonzalo de Concha, vecino de Alcira, inculpado de haber capturado cuatro sarracenos en el saqueo de la morería de la villa; pero que se le obligue a contribuir también a la cantidad impuesta como castigo general

P[etrus], Aragone Rex, / nobili et dilecto viro Roderico Eximeni de Luna, procuratori Regni Valencie vel collectori condempnacionis quam nos fecimus in Algezira, salutem et dilectionum. Gondiçalbus de Concha habitator de Algezira nobis supplicando ad stranie per cum ipse racione barregii morerie de Algezira singulariter / esset condempnatus racione quatuor sarracenorum quos confessus fuit se habuisse de dicto barrigio, quo prout nunc asserit non iamodum barregii / set alias cepit dictos quatuor sarracenos et eos tradidit baiulo et iusticie de Algezira super quo suplicauit probacionem suam recepi. Nos autem / recepcionem testium et examinacionem et probacionem istius negocii comisimus venerabili Episcopo valentino per quem nobis constat predictum Gonçalbum sufficienter / probasse predicta. Quare 
mandamus uobis quatenus racione predicte singularis seu specialis condempnacionis non petatis uel rccipiatis aliquid ab eo. Immo, / si aliqua recepistis ab eo racione predicta, visis presentibus restituatis sibi et restitui faciatis. Volumus tamen quod ipso in generali con- / dempnacione contribuat simul cu maliis conuicinis suis. Datum Valencie, idus februarii anno Domini $\mathrm{M}^{\circ} \mathrm{CC}^{0} \mathrm{LXX}^{\circ}$ septimo.

Valencia, 19, febrero, 1278.

(Reg. 40, fol. 69)

Orden al baile, justicias y vecinos de Alcira, de que reconozcan a Martín de Seta como colector, en nombre del rey, de la cantidad que. tenía que pagar la villa como castigo por el saqueo de la morería

P[etrus], Dei gratia Rex Aragonum, fidelibus suis baiulo, iusticie et vniuersis hominibus Algezire, salutem et gratiam. Noveritis / quod nos mitimus Martinum de Seta de domo nostra pro levandis, recipiendis et colligendis pro nobis et nomine nostro denariis / condempnacionis de Algezire. Quare mandamus uobis quatenus de omnibus predictis denariis respondeatis et tradeatis loco nostro / dicto Martino de Seta latori presentium uobis, mandamus dicto Martino quod uos et bona vestra compellat ad predicta. / Datum Valencie, XI kalendas martii anno predicto.

Valencia, 1, abril, 1278.

(Reg. 40, fol. 78 v)

Despacho dirigido a Martín de Seta diciéndole que si los vecinos de Carcagente, Ternils y Algemesi prueban que no intervinieron en el saqueo de la morería de Alcira, que se les perdone

P[etrus], Dei gratia Rex Aragonum, fideli portario suo Martino de Seta, salutem et gratiam. Mandamus uobis quatenus si homines de Carcaxen et de / Ternils et de Algemesi probouerint idonee quod ipsi tempore barrigii morarie de Algezira essent tantum remoti a dicto barrigio / quod non possent ad subuencionem ipsius ad tempus venire, non compellans eos ad contribuendum in condempnacionen / quam nos imposuimus vniuersitati de Algczira causa barrigii supradicti, prout hoc in sententia dicte condempnacionis iam / est expressum et exceptum. Datum Valencie, kalendas aprilis anno predicto. 
Valencia, 15, abril, 1278.

(Reg. 40, fol. 92 v)

Despacho dirigido al justicia de Alcira y a Martín de Seta para que no graven a los caballeros por razón del saqueo de la morería

Pletrus], Dei gratia Rex Aragonum, fidelibus suis iusticie Algesire et Martino de Seta de domo nostra, salutem et gratiam. Mandamus / quatenus si milites Algezire proposuerint coram uobis aliquas deffensiones propter quas secundum tenorem sentencie late contra (?) universitatem / super facto morarie intelligi non debeant in condempnacionem ipsius sententie, ipsas deffensiones eorum admitentes ipsos uel [bona] / eorum contra tenorem ipsius sententie in aliquo non gravetis. Datum Valencie, XVII kalendas madii anno predicto. 